\title{
LOS ARCHIVEROS DE LA PRIMERA SECRETARÍA DE ESTADO (SIGLO XVIII)
}

\author{
Por Jesús PRADELLS NADAL y \\ Ramón BALDAQUÍ ESCANDELL \\ Universidad de Alicante
}

\section{LOS ARCHIVEROS DE LA SECRETARÍA DE ESTADO EN EL SIGLO XVIII}

Desde el siglo XVI los archivos cobran una nueva magnitud con la paulatina burocratización que comporta la concentración de poder en manos de las monarquías modernas. El archivo representa, en palabras de Bautier, el «arsenal de la autoridad» del Príncipe e instrumento imprescindible de la administración cuya organización, en cierto modo, queda reflejada en la estructura orgánica que se da a sus fondos ${ }^{(1)}$. Es en este siglo cuando, en la Corona de Castilla, se funda en Simancas un archivo centralizado para la documentación oficial como culminación de un largo proceso que, iniciado por Fernando el Católico en 1509, se consolida entre 1540 y 1545 , para adquirir definitivo impulso durante el periodo del archivero Diego de Ayala quien, junto con los secretarios Vázquez y Zayas, redactaron las ordenanzas promulgadas en la Instrucción de 24 de agosto de 1588 que, con gran sentido de modernidad archivística, regulaba la instalación, recogida, transferencias y tratamiento de la documentación, el régimen de personal y el servicio del archivo a la Administración y a los particulares ${ }^{(2)}$.

Consecuencia de este concepto de archivo es la atención preferente que se da a los documentos tocantes al Real Patrimonio y los derechos de la Corona (3), así como la importancia de mantener los papeles en buen orden y condiciones de rápida accesibilidad para las necesidades administrativas, por lo que no sólo se dan normas para el archivo central, sino también para los archivos de gestión de los Consejos ${ }^{(4)}$. Interés reglamentista que durante el siglo XVII se manifiesta en las nuevas ordenanzas elaboradas para Simancas en 1633, en un nuevo intento de vigilar la gestión del archivero y facilitar la posible utilización de los documentos por la administración de Madrid. La distancia a Simancas y las necesidades 
de una gestión más ágil, impulsaron a Felipe IV, por Decreto de 13 de agosto del mismo año, a disponer se organizase un archivo general en Palacio que no llegaría a llevarse a efecto ${ }^{(5)}$.

El siglo XVIII dará muestras también de un gran interés por los archivos. Éstos serán objeto de la atención de los eruditos que planificarán la publicación de importantes colecciones diplomáticas ${ }^{(6)}$. Es el momento en que nace el Archivo de Indias sevillano concebido como un depósito de fuentes para la historia oficial de las posesiones españolas y que, por esta funcionalidad histórica, supone un precedente de una forma de considerar los archivos que cuajará en el siglo XIX ${ }^{(7)}$. Pero el Archivo de Indias, centralizando los documentos de tema americano sin valor administrativo inmediato, tiene sobre todo una función administrativa que es la que preferentemente se asigna a los archivos en el siglo de las Luces ${ }^{(8)}$.

Manifestación privilegiada dentro de estos usos administrativos de más altos vuelos son las grandes campañas de investigación en archivos reales y eclesiásticos que tratan de fundamentar las aspiraciones regalistas de la Corona frente a la Curia romana. "Tendencia exhumadora», como la calificara Olaechea que se remonta a los Reyes Católicos con las actividades del Abad de Alfaro, cobra rasgos destacados con Felipe II y las comisiones de Ambrosio de Morales, Martín de Córdoba y Juan de Berzosa. Los documentos recopilados por Jerónimo de Chirivoga durante el reinado de Felipe III servirían en buena medida para la redacción del Memorial de Chumacero y Pimentel. En el siglo XVIII una Junta Reservada formada en 1710 y específicamente creada para entender en los negocios de Patronato supone la continuación de esta vía en la que destacará el abate Vivanco. Más amplias dimensiones alcanza en 1749 con la comisión de archivos formada bajo la dirección inmediata del P. Burriel, a la sombra de Carvajal y del P. Rávago, confesor de Fernando VI ${ }^{(9)}$.

El interés inmediato por la organización y funcionamiento de los archivos desde el punto de vista administrativo queda plasmado en las sucesivas visitas que se realizan a lo largo de los siglos XVII y XVIII ${ }^{(10)}$ y en los esfuerzos por ordenar los archivos de los diversos Consejos y Órdenes Militares que quedan reflejados en el conocido informe de Santiago Agustín Riol ${ }^{(11)}$. En los archivos de Consejos y Secretarías, el personal dedicado a la ordenación y custodia de los fondos presenta características muy diversas por la falta de reglamentaciones. Un decreto de 12 de marzo de 1696 que disponía el nombramiento de archiveros en todos los Consejos no llegó a tener realización práctica ${ }^{(12)}$. Será durante los primeros años de la nueva administración borbónica cuando los Consejos, y sobre todo, las potenciadas Secretarías de Estado y del Despacho, organicen sus propios reglamentos internos, paulatinamente reîormados y precisados a lo largo de la centuria ${ }^{(13)}$.

Si nos situamos en la parcela que nos interesa dentro del aparato administrativo del siglo XVIII, la Secretaría de Estado, se hace evidente que la conservación de los documentos no dependía tan sólo del gran número de expedientes tramita- 
dos, sino de la cantidad de competencias que a lo largo del siglo se acumularon, pues, a las derivadas de su función como centro director de las relaciones internacionales y gestor del cuerpo diplomático, se añadieron muchas otras ramas de la administración interna. Con el "estirado» José Moñino, Conde de Floridablanca, este fenómeno alcanzaría su cota más alta, y tras las reducciones introducidas por Aranda durante su breve interinazgo, serían de nuevo desaforadamente ampliadas por Godoy ${ }^{(14)}$.

El curso normal de los expedientes que confluían en la Secretaría era esquemáticamente el siguiente: el Oficial Mayor distribuía los papeles, de acuerdo con el reparto vigente en negociados o mesas a los Oficiales que formaban, mantenían abiertos, extractaban y documentaban los expedientes antes de pasarlos al «Ministro» Secretario de Estado. En función de la resolución adoptada se daba el curso pertinente y se dejaba constancia en el Archivo. Éste resultaba fuente indispensable en cada una de las oficinas ministeriales y Secretarías de los Consejos, al que era necesario recurrir para esclarecer, buscar precedentes, comprobar fórmulas, redactar nombramientos, etc., pues muchas ramas de los negocios carecían de más normativa que la proporcionada por la costumbre inveterada.

El trabajo de los archiveros no se circunscribía a guardar los expedientes cerrados sino a una labor permanente de ordenación, e incluso de rescate de algunos que en su tiempo no se habían considerado con la suficiente entidad como para merecer una reseña especial, y desempolvar otros muchos en busca de un precedente que apoyase o contradijese una solicitud de las que a diario se presentaban.

La organización de «la papelera» de la Primera Secretaría, desde una perspectiva moderna, ha merecido toda clase de comentarios, incluso de destacados profesionales del oficio archivístico. Gómez del Campillo juzgaba, quizás con extremada dureza, la cualificación y poco feliz gestión de los archiveros de la Secretaría de Estado:

«En el Archivo de Estado y ya de antiguo, no hubo nunca archivos (sic, por archiveros) de cultura que fuesen capaces de coordinar los numerosos y variados fondos que a él afluían procedentes de las múltiples negociaciones que España sostenía con todo el mundo» ${ }^{(15)}$.

Pero en el funcionamiento cotidiano de la Secretaría de Estado la larga permanencia de los Oficiales al frente de una misma mesa o negociado suplirá algunas de las funciones de los archiveros. Tal es el caso durante el largo período en que Floridablanca permanece al frente de la Secretaría (1776-1792), mientras que, tras su defenestración, se advierte un período de desconcierto con una evidente ralentización en el despacho de los asuntos cotidianos. La escasa experiencia que podían adquirir los Oficiales por el rápido ritmo de promociones que se impuso durante los gobiernos de Godoy, Saavedra, Urquijo o Cevallos, con la sustitución de la vieja guardia de los empleados en el servicio exterior y con la renovación de la escala de los Oficiales en la Secretaría —-muchos de ellos víctimas de las banderías cortesanas - se hizo ya manifiesta durante la primera época de Go- 
doy y se agrava notablemente con sus sucesores. La continua petición de antecedentes sobre asuntos hasta entonces de trámite, resulta característica de Manuel Godoy, mientras que Saavedra confiaba más los asuntos rutinarios a los Oficiales ${ }^{(16)}$.

Buena parte de la confusión administrativa sería evitada gracias al trabajo del archivero Francisco Hurtado en la formación de extractos de antecedentes para ilustración de los efímeros Secretarios y Oficiales. Frente a las vertiginosas variaciones en la plantilla de estos últimos que se produce a fin de siglo, los archiveros y sus auxiliares destacan - salvo la excepción de Monjardín - por la larga permanencia en sus empleos. De hecho, se les puede considerar en este período como la memoria viva de la Secretaría, pues, por lo general, llegarán a Archiveros tras una larga carrera como Oficiales de Archivo o incluso como meritorios dentro de la misma Secretaría, lo que los dotaba de experiencia y habilidad para desempolvar los precedentes necesarios entre los miles de legajos generados por la administración diaria.

Una visión general de estos ritmos internos nos la puede proporcionar, independientemente de la mayor importancia política de los cambios de Ministros y Oficiales, una escueta visión de la evolución personal de los Archiveros de la Secretaría de Estado a lo largo del siglo XVIII.

\section{a.-EL ARCHIVO Y LOS ARCHIVEROS \\ DE LA PRIMERA MITAD DEL SIGLO}

Desde 1707 el archivo de la única Secretaría de Estado y del Despacho Universal estuvo servida por don Bernardo Muñoz Tovar, que había sịdo Agente Fiscal del Consejo de Cruzada y comisionado para el arreglo de sus papeles en $1699^{(17)}$. Pero como las demás plazas, la de Archivero no estaba vinculada en propiedad a quien la ejercía, sino que se daba en comisión, pues la práctica normal era que cada nuevo Secretario se rodease de los Oficiales de su confianza, procedentes por lo general de las distintas oficinas de la administración y en particular de las Secretarías de los Consejos ${ }^{(18)}$.

El Real Decreto de 30 de noviembre de 1714, por el que se reformaba el esquema de la organización interna de la administración, dispuso que una de las nuevas cinco Secretarías debía correr con

«todo lo tocante a Eclesiástico y de Justicia y Jurisdicción de los Consejos y Tribunales») ${ }^{(19)}$.

Este departamento, bajo la dirección de Manuel Vadillo y Velasco, recibió desde entonces el nombre de Secretaría de Justicia, Gobierno Político y Hacien$d a$. En ella continuó sus servicios Bernardo Muñoz,

«pues a este Archivo se remitían los Papeles que iban causando en las demás Secretarías»,

hasta su muerte en $1722^{(20)}$. Durante este período tuvo lugar el traslado de los Consejos desde el Palacio Real al que había ocupado Mariana de Austria, cono- 
cido por ello como «de la Reina Madre» y a partir de entonces «de los Consejos».

El insuficiente espacio de que se disponía en el nuevo recinto motivó la orden de trasladar al Castillo de Simancas los papeles que no tuviesen un valor administrativo inmediato. Desde 1718 fueron remitidos a aquel Archivo la mayor parte de los documentos del último período de la Casa de Habsburgo en España,

«pero esto se executó con tan inconsiderada celeridad, que no dió lugar á que quedase en las Oficinas toda la razón que convenía a los que se sacaban de ellas» ${ }^{(21)}$.

Hasta el año 1738 no comenzaron las diferentes Secretarías a tener personal propio encargado de ordenar, clasificar y archivar la documentación generada por el trabajo diario. Pero la consideración concreta de estos empleados en el organigrama de las Secretarías era, cuando menos, dudosa. En 1763, con motivo de la integración de los Oficiales de la covachuela en el recién creado Montepío, se suscitaron problemas que evidenciaban la poca claridad con que se había definido el empleo de Archivero, y si debía considerarse con el mismo rango que los Oficiales y por tanto acreedor a sus beneficios. Al respecto, López Cordón señalaba cómo el Archivero

«que solía ser nombrado secretario de la reina, y cuyas funciones se hicieron cada vez más imprescindibles»,

no pertenecía a la carrera administrativa y se regía por patrones específicos ${ }^{(22)}$. Pero, aunque no podían aspirar al ejercicio de otras funciones por ascenso dentro de la jerarquía establecida para los Oficiales, en los inicios, y también a fines de siglo, contaban con la consideración de Oficiales con posibilidad de promoción hasta el equivalente a Oficial segundo en todo lo relativo a honores y prerrogativas para la percepción de sobresueldos, mesas y regalos, etc.

La no inclusión del Archivero Benito Martínez Gómez Gayoso en el Montepío de la Secretaría de Estado motivó la inmediata elevación de una representación a Grimaldi que, en sí misma, es un ejemplo del buen uso y perfecto dominio de su profesión. Recopilaba en él todos los antecedentes que

"claramente demuestran que el Archivero es Oficial de la Secretaría», y en consecuencia, que tenía todo el derecho a ser incluido en el nuevo organismo de pensiones. Entre otros documentos, esgrimía Gayoso un oficio fechado en 1714 al Obispo de Gironda, entonces Secretario de Hacienda, donde figuraba la orden expresa de pagar al archivero los atrasos de su sueldo

«en los mismos plazos y en la misma forma que a los demás Oficiales de las Secretarías del Despacho».

Alegaba igualmente Martínez Gayoso que, en otras ramas de la Administración, gozaban también de la categoría de Oficiales, tal como constaba en los títulos expedidos a los de Gracia y Justicia. Sin embargo, es cierto que el reconocimiento de su categoría como Oficiales no implicaba su inclusión en el escalafón establecido desde mediados de siglo para regular los ascensos:

«Y esto es así -escribia don Benito- y los que han salido a las pla- 
zas de opción de las Secretarías han sido por nueba gracia. Es de presumir que mirando a esto se señalaron tan decentes sueldos a los Archiveros de las Secretarías del Despacho, Muñoz, Riol y Gayoso» ${ }^{(23)}$.

Sueldos en realidad muy decentes, complementados con sustanciosas asignaciones por los de otros cargos y comisiones extraordinarias que, con relativa frecuencia, se les encomendaban. El primer sujeto, al que hicimos referencia, don Bernardo Muñoz, sumaba a los 27.000 reales anuales como Archivero con categoría de Oficial tercero, el que gozaba como Agente para la negociación con Roma, que ascendía a casi 200 ducados anuales más.

Similares estipendios tendría su sucesor don Santiago Agustín Riol. Paje de bolsa del Marqués de la Mejorada, Riol recibió el encargo de su amo de continuar la ordenación de los documentos de la Secretaría del Patronato, tarea a la que celosamente se entregó desde 1697. En plena Guerra de Sucesión, siendo Oficial tercero de la Secretaría del Patronato, representó los méritos adquiridos en esta tarea, y tres años más tarde, en 1711, fue comisionado para visitar el Archivo de Simancas en compañía de don Luis Curiel de Tejada, Fiscal del Consejo de Castilla, para buscar documentos sobre el Real Patronato, y de nuevo recibió un encargo similar entre abril y noviembre de 1713. Su esfuerzo exhumador, según propias lamentaciones,

«no mereció más que el desprecio de los Ministros de aquel tiempo..., ni obtuvo más premio que el odio y las crecidas deudas que contrajo con estos viajes".

Los largos años pasados en el manejo de los documentos del Patronato, habían dado a don Agustín un aura de especialista de tal calibre que, en los años de 1707 y 1710 en que la Corte pasó a Burgos y Vitoria sin llevar documentos patronales, la Cámara despachó tan sólo a base de las noticias con que la iluminaba Riol y en 1714 fue nombrado para asesorar a los cuatro Secretarios en jefe de la Cámara, a fin de evitar que el archivo se dividiera.

El Fiscal general Melchor de Macanaz, que había utilizado documentos sacados a la luz por don Santiago para preparar las negociaciones con Roma, se fijó en él, y en abril de ese mismo año le recomendó para la Oficialía Mayor de la Cámara. Agente de preces en Madrid, el 6 de julio de 1722 se le confirió también el empleo de Archivero de la Primera Secretaría, hasta que se vio envuelto en un turbio asunto de apropiación de fondos de bulas de pensiones a principios de 1732, que supuso su caída en desgracia ${ }^{(24)}$.

Otro de los titulares durante esta primera etapa fue Juan Cascos Villademoros que cuando llegó al Archivo contaba con largos años de experiencia en el servicio diplomático pues había servido en la legación holandesa y viajado a Rusia como secretario en la embajada del Duque de Líria ${ }^{(25)}$. Destinado al Archivo de la Secretaría en octubre de 1738, a diferencia de Riol, su nombramiento no emanó de Gracia y Justicia sino directamente de la Secretaría de Estado. Esta nueva circunstancia la considera explicada Martínez Gayoso veinticinco años más tarde por hechos fortuitos: 
«...haviéndose quemado el Archivo principal en Palacio quedó la de Estado con más papeles que las demás y por haverse destinado en el Retiro sitio para el Archivo común, se agregó el Archivero que sucedió a Riol a la Secretaría de Estado» ${ }^{(26)}$.

La sucesión de Cascos Villademoros presentó algunos inconvenientes. En principio se pensó como sustituto en el entonces Oficial traductor Juan de Iriarte que, desde su llegada a Madrid en 1724 había sido empleado como preceptor de los hijos de los Duques de Béjar y Alba y del Infante Manuel de Portugal, gracias a sus relaciones con el Bibliotecario Juan de Ferreras y con el Embajador inglés Clarke. Oficial escribiente en la Biblioteca Real desde 1729 y Bibliotecario tres años más tarde, sería nombrado en febrero de 1742 Oficial traductor de la Primera de Estado por medio del ya marqués de Villarias ${ }^{(27)}$.

Con su llegada, sólo anterior en unos meses a la salida de Cascos Villademoros, se pensó reunir en él los empleos de Traductor y Archivero para ahorrar así en sueldos - al estar dotado el primero con 11.000 reales, se le asignarían por el segundo sólo 15.000. La propuesta no tuvo resolución favorable y en 1747 se propuso para la plaza del Archivo a Benito Martínez Gómez Gayoso ${ }^{(28)}$.

\section{b.-LOS ARCHIVEROS EN LA SEGUNDA MITAD DEL SIGLO}

Cinco fueron los titulares que pasaron por el Archivo entre 1747 y 1808 . Sobre Benito Martínez Gómez Gayoso disponemos de un panorama biográfico que relaciona su carrera con el grupo canario de la corte madrileña. Nacido en el lugar de Parada de Arriba en la isla de Tenerife, apenas sabemos nada de sus primeros años ${ }^{(29)}$. Debió de cursar sus estudios universitarios en Salamanca donde, durante dieciocho años, fue profesor de «Filosofía, Cánones y Humanidad». Participó en numerosas comisiones por encargo de la Secretaría de Gracia y Justicia en apoyo de las posiciones regalistas de la Corona:

«Trabajó todos los documentos de la Orden de Calatrava, traduciendo muchas Bulas, Privilegios y Definiciones y capítulos de ella contra las convocatorias que suscitaron los Monjes Cistercienses Franceses de Claravall y Borgoña que querían volver a la posesión de las encomiendas de las Órdenes Militares de España el año de $1737{ }^{(30)}$.

Participó también en la clarificación del Derecho de Patronato sobre los foros de la dotación que hiciera Sancho el Mayor de Navarra al monasterio de San Millán de la Cogolla, y aparece también como autor de un Arte Español, en que se trataba de reducir a fórmulas metodológicas la gramática castellana. En premio a sus trabajos recibirá la plaza de Archivero de la Cámara de Castilla, donde prosiguió su tarea como traductor y revisor de bulas, privilegios y ejecutorias durante ocho años. Finalmente, en 1747, fue trasladado a la Secretaría de Estado.

No dedicó Martínez Gayoso todo su tiempo a los asuntos del Archivo, sino que se ocupó de varios entretenimientos, como se denominaba entonces a las comisiones extraordinarias. Uno de ellos sería el que a instancias de Carvajal se le 
encomendó para copiar y recapitular los veintidós tomos que formaban las colecciones que por orden de Felipe II había recopilado en Roma el Embajador Francisco Vargas junto con el secretario Juan de Berzosa. Algo más de tres años emplearía Martínez al frente de seis auxiliares en finalizar la empresa, que si no fue la única, destaca por su mayor trascendencia ${ }^{(31)}$.

El trabajo cotidiano en el Archivo era también de consideración y él mismo describe cómo hubo de realizar sucesivas

«coordinaciones, arreglos y memorias de suma vasticidad (sic) de los papeles del Archivo, que ascienden a ochenta ramos de su comprensión y composición; además de la custodia, zelo, aseo y limpieza de ellos...) ${ }^{(32)}$.

La amplitud de la labor hizo necesaria la contratación de personal auxiliar de plantilla. El 9 de febrero de 1747 fue designado como Oficial de archivo Bernardo García Aedo con un sueldo anual de 5.000 reales que conservaría hasta 1754 en que, reclamado por el Conde de Valparaíso, fue promocionado a la Secretaría de Hacienda. También en 1747 sería empleado José Marcos como ayudante para la traducción de bulas y breves preparatorios para el Concordato de $1753^{(33)}$. Contó éste con 6.000 reales de sueldo, a los que se añadirían otros 300 en 1754 en atención a su aplicación y méritos, aunque, en realiaad, fueron mercedes concedidas por la feliz conclusión del Concordato. En octubre de 1763 García Aedo se integraría en la plantilla de la Secretaría de Gracia y Justicia ${ }^{(34)}$.

Vacante la plaza de Oficial de archivo, fue cubierta en febrero del año siguiente con el controvertido José Clavijo Fajardo, que sería cesado apenas unos meses más tarde como consecuencia del famoso escándalo que provocaron sus lances amorosos con la hermana de Beaumarchais ${ }^{(35)}$. La designación de un nuevo oficial quedó en suspenso y en consecuencia también la formación de repertorios e índices que Gayoso dirigía por aquellos días. Durante estos años el Archivero contó también con el auxilio del joven Francisco Javier de Santiago Palomares que, desde que se trasladaron los papeles de la Secretaría al Palacio nuevo, había quedado como meritorio sin sueldo para colaborar en el trabajo de reconocer y ordenar los papeles del Escorial. Palomares, colaborador en las pesquisas del P. Burriel en Toledo y destacado calígrafo y paleógrafo ${ }^{\left({ }^{(6)}\right.}$, sería nombrado Archivero en 1794, después de una larga carrera donde no faltaron repetidos desaires y sofiones. Cuando en 1766 Grimaldi decidió cubrir la plaza de Oficial de archivo, no recayó el nombramiento sobre el entretenido Palomares sino en José Belezar, a pesar de que Martínez Gayoso había mediado en favor de su protegido. Efectivamente, Gayoso insistió en la necesidad de personal para subsanar el desorden del Archivo desde el último traslado, por lo que la ayuda de Palomares resultaría imprescindible para continuar con la formación de un inventario con sus índices por su experiencia

«en esta clase de trabajos que le es tan genial, por el curso y conocimiento que tiene de varios Archivos del Reyno y, especialmente, en el del Monasterio de San Lorenzo el Real» ${ }^{(37)}$. 
donde había pasado dos años comisionado con una pensión de 5.000 reales sobre las Rentas Provinciales.

Como siempre los sueldos eran el tema más espinoso para la ampliación de plantillas. Aunque Gayoso propuso la fórmula intermedia de que Belezar y Palomares compartiesen los 9.000 reales del primero y los 5.000 del segundo, equivalentes a los 14.000 que habían percibido los anteriores Oficiales, tampoco esta vez sus propuestas fueron aceptadas, con lo que Palomares permanecería durante algunos años más como entretenido ${ }^{(38)}$.

Benito Martínez murió en Madrid el 4 de diciembre de 1787, a la provecta edad de ochenta y siete años. Los achaques, especialmente desde la muerte de su primera esposa en 1774, lo mantuvieron alejado del Archivo al cuidado de la vizcaína natural de Nestosa, María Caro Escudero, con la que había contraído segundas nupcias a la prudente edad de setenta y cinco años ${ }^{(39)}$. En esto puede considerarse como otro más de los ejemplos de la sana longevidad que parece gozaron los funcionarios empleados en la Secretaría de Estado.

El Oficial Belezar ocupó la vacante dejada por Martínez Gayoso. Natural de Valencia, su carrera en la Primera Secretaría había dado comienzo hacia 1747. Desempeñó empleos de subalterno y secretario en las legaciones de Dinamarca y Suecia bajo las órdenes del Marqués de Puentefuerte, del Vizconde de Herrería y posteriormente del Conde de Lacy. Después de una breve estancia en Nápoles fue nombrado por Grimaldi para la vacante de Oficial del Archivo en 1766, y un año más tarde llegaba a Madrid para tomar posesión de su nuevo destino. En realidad, tuvo que actuar como archivero efectivo desde 1779, debido a la avanzada edad y los alifafes de Gayoso hasta su nombramiento como Archivero en 15 de febrero de 1787, después de veintiún años como Oficial ${ }^{(40)}$.

Su situación económica, a pesar del sueldo, los extras y alguna que otra gratificación extraordinaria, nunca fue boyante, y desde luego no era comparable a la que habían tenido sus antecesores, debido a la estabilidad que los sueldos reglamentarios mantuvieron desde 1749. Cuando el Oficial Mayor recomendó a Floridablanca una petición de ayuda crematística de Belezar, le hacía notar como, cerca ya de los setenta años,

«no tiene otro auxilio por ninguna parte, antes sí algunos parientes pobres que le vienen de Valencia».

La propuesta no sólo fue aceptada, sino que significó un aumento de 3.000 reales anuales libraderos por la Dirección de Correos para él y también para el Oficial Palomares ${ }^{(41)}$.

Fallecido José Belezar, quedaron en el Archivo los Oficiales Palomares y Francisco Hurtado. De acuerdo con la costumbre tan difundida en la Administración de conceder los ascensos por antigüedad, debería haber ascendido el primero, pero de nuevo sería relegado por la designación de Alfonso de Monjardín el 9 de marzo de $1792^{(42)}$. En el mes de febrero anterior Floridablanca había sido cesado como Secretario de Estado y comenzaba el interinazgo de Aranda. Para la plaza de Archivero el Conde aragonés nombró a un viejo subalterno suyo, al tiempo 
que redistribuía las mesas y concedía aumento de sueldos a los Oficiales en el llamado arreglo de 1792. Una Real Orden de 13 de marzo incrementó el sueldo de Palomares hasta 16.000 reales como Oficial primero del Archivo y hasta 10.000 el de Francisco Hurtado, pero eliminaba los goces extraordinarios que habían tenido con Floridablanca.

Las condiciones en que Aranda concedió el empleo a Monjardín fueron excepcionales. En el oficio de nombramiento, además del sueldo reglamentario se le asignaban 10.000 reales equivalentes a la gratificación que Floridablanca fijó en 1786 como substituto de todos los extras de Navidad y San Juan que percibía Belezar. En julio recibía otros 2.000 reales anuales sobre Correos y apenas un mes más tarde se le concedió el preceptivo título de Secretario de la Reina con los correspondientes goces. Es decir, un total de 45.000 reales anuales, lo mismo que percibía un Consejero de Castilla. Conservaría también el sueldo de la plaza de Oficial de la Contaduría del Canal de Murcia que sirviera años atrás. De ella lo había sacado Aranda en 1784 para llevarlo a París donde trabajó como escribiente de la Secretaría hasta la dimisión del Conde en 1787. Pero la suerte de Monjardín quedó ligada a la de su jefe. En noviembre de 1792 Godoy asumía la dirección de la Secretaría de Estado, y Monjardín se retira desde El Escorial a Madrid, después de entregar las llaves de los papeles. Allí continuó su trabajo hasta el destierro de Aranda a Jaén como resultado del agrio enfrentamiento entre el Conde y el Duque de la Alcudia en el Consejo de Estado. El mismo día 14 de marzo de 1794 en que Aranda partía para el destierro, un oficio del Duque comunicaba a Monjardín la prohibición de poner los pies en el Archivo. Cinco días tardó en recibir otro con su nombramiento como Comisario de Guerra con orden de incorporarse de inmediato al Ejército destinado en el Rosellón. De nada sirvieron las peticiones de Monjardín para no ser destinado al frente, y en Barcelona, camino de la frontera, recibiría la notificación de haberse mandado anular la expedición del título de Secretario real ${ }^{(43)}$.

El recoger los papeles de Aranda llevaría a Godoy tan de cabeza como meses atrás había llevado al propio Conde capturar los de Floridablanca. El asunto no solamente supuso la desgracia del Archivero arandista, sino que al parecer, también significó el primer tropiezo grave del Oficial Mayor José Anduaga, al no haberse atrevido a impedir que el Conde recogiera algunos de sus papeles personales ${ }^{(44)}$. Palomares, Oficial archivero desde $1784^{(45)}$ fue el encargado de formar un índice de los que se recogieron en casa de Aranda ${ }^{(46)}$.

Las realizaciones de Palomares en el Archivo fueron numerosas desde que iniciara su «largo y trabajoso noviciado» en 1764. Floridablanca lo designó en 1785 como coordinador para la impresión de la España dividida en Provincias... ${ }^{(47)}$, resultado de las relaciones que se había ordenado formar a los Intendentes y Arzobispos. Como Sempere y Guarinos hiciera más tarde, Palomares hizo notar enseguida la gran imperfección de las relaciones que remitían los Intendentes:

«De éstas, sólo las de Segovia y Valencia están bien. Y para que todas 
fuesen perfectas convendría imprimir una de ellas que sirviese de planta a las demás, enviando el modelo con carta circular, encargando la buena ortografía (...). Con estas noticias [se] hará un Î́ndice topográfico mui curioso y útil de todos modos» ${ }^{(48)}$.

El primero de los índices que remitió a Floridablanca, que comprendía cuarenta y ocho cuadernillos con un anexo de todas las Justicias y Gobiernos, no fue del agrado del Ministro, pero permaneció durante los cinco años siguientes al frente del proyecto. Mantuvo correspondencia directa con Intendentes y Obispos para solicitar nuevos datos y precisiones y se encargó también de los detalles de la edición hasta $1790^{(49)}$.

El fulminante cese de Monjardín propició finalmente el ascenso de Palomares a la plaza de Archivero. Al remitir al Duque de Alcudia los índices que acababa de formar de los papeles de Aranda, aprovechó para solicitarlo y exponer a la par los méritos del Oficial segundo - plaza que había sido creada en 1786Francisco Hurtado de Mendoza,

«mozo hábil, silencioso y bien educado que posee el latín, francés e inglés y que ha adquirido por su aplicación mucho conocimiento de los papeles») ${ }^{(50)}$.

El 27 de marzo de 1792 Godoy decide conceder el grado de Archivero a Palomares y la plaza de Oficial primero a Hurtado de Mendoza ${ }^{(51)}$. No pudo disfrutar mucho tiempo de su nueva situación, pues, en los primeros días de 1796, Francisco Hurtado comunicaba al Príncipe de la Paz cómo Palomares se sintió indispuesto. Los médicos diagnosticaron una vehemente pulmonía que terminó con su vida el 19 de enero. El mismo Hurtado se hizo cargo de representar a Godoy el desamparo en que quedaba su familia, con «una niña baldada de corta edad》 ${ }^{(52)}$.

La promoción de Hurtado no tuvo lugar, a pesar de sus reiteradas solicitudes, hasta febrero de $1796^{(53)}$. Por estas fechas, llevaba ya once años en empleos similares. Había comenzado su carrera en la Secretaría de la Junta de Comercio, donde permaneció seis años hasta que en 1787 fue nombrado Oficial segundo del Archivo de Estado. Dominaba varias lenguas y todo indica que permaneció soltero, aunque no impenitente, pues, además de mantener a su madre y una agostada «hermana en estado honesto», eran conocidas las obligaciones que tenía con una numerosa parentela. Hurtado permaneció al frente del Archivo hasta 1810 en que abandonó el Madrid napoleónico para pasar al lado de la Junta, en cuya Secretaría continuó sus servicios ${ }^{(54)}$.

\section{c.-LA SAGA PALOMARES: EDUARDO Y ANTONIO DE SANTIAGO}

Antes de ser nombrado Archivero Francisco Hurtado, se abrió un plazo de presentación de solicitudes para cubrir las vacantes. Las numerosas instancias nos permiten calibrar lo pretendidos que resultaban estos empleos. Algunos de los aspirantes estaban muy bien cualificados, como Juan Ignacio Cascos, sobrino del 
antiguo Archivero y empleado desde hacía veintitrés años en la Biblioteca de los Reales Estudios de San Isidro. Merece también destacarse la figura de Vicente González Arnao, catedrático de Física experimental en la universidad de Alcalá, y que declaraba tener amplios conocimientos de jurisprudencia, griego, árabe, francés, italiano, portugués e inglés. Miembro de la Real Academia de la Historia, era autor de un Discurso de Colecciones de Cánones, impreso a costa del erario real, y de una Historia Civil de España ${ }^{(55)}$. Desestimadas las veintidós solicitudes para Archivero y once para Oficial, Godoy nombraba a Hurtado para la primera, otorgaba la de Oficial primero a su secretario Vicente Juliá de Malveau, y la de Oficial segundo a Santiago Montes (56).

Una tercera plaza de escribiente de plantilla le fue concedida a Eduardo de Santiago Palomares. Ya en 1795 el Archivero Francisco Javier de Santiago solicitó el empleo de Oficial segundo, en la práctica un escribiente meritorio, para su hijo Eduardo, cuando apenas contaba trece años de edad. Había resaltado entonces su padre los estudios de Gramática y las habilidades caligráficas del muchacho, al que creía de vivo ingenio "para seguir cualquier carrera»" ${ }^{(57)}$.

Eduardo compaginó el trabajo del Archivo con los estudios de «Latinidad y Filosofía» que terminó en 1799, y cuyos gastos de obtención de grado sufragó con ayuda de la Secretaría. En 1802 se le presentaría la primera oportunidad de ascenso con la salida de Vicente Malveau, pues aunque la Oficialía se confirió a Juan Antonio Fernández, no llegó a tomar posesión efectiva y facilitó el nombramiento de Eduardo de Santiago con calidad de interino en abril, y como propietario desde julio de $1803^{(58)}$. Su carrera se vio truncada por la permanencia al lado del gobierno de José I, con el que ocupó la plaza de Oficial segundo de la Secretaría del Ministerio de Asuntos Extranjeros. Comprendido de pleno en el decreto de castigo de 30 de mayo de 1814, se encontró sin empleo y con la confiscación de los bienes de su mujer Inocencia Ugalde de Treviño, con la que había contraído matrimonio en 1806 . No pudo conseguir la documentación necesaria para la depuración y durante los años siguientes redactó una verdadera batería de memoriales para penitencia de los Oficiales de la Secretaría, en que se presentaba como una más de las víctimas de las fuerzas desatadas del ciego destino y cebadas sobre su fidelísima persona. Finalmente, en 1833, la Reina accedió a sus demandas de empleo y se le recomendó para una plaza subalterna en Fomento. Hasta entonces, durante casi veinte años, había salido a flote como corrector en la Imprenta Real ${ }^{(59)}$.

El tercer miembro de la familia Palomares, Antonio de Santiago, comenzó como agregado al Archivo de la Secretaría bajo el ministerio de Saavedra en junio de 1798 , a los veintiséis años de edad ${ }^{\left({ }^{(6)}\right.}$. No carecía de experiencia, pues anteriormente había sido Oficial de la Secretaría de Intendencia del Ejército de Caracas y secretario del Superintendente. Cursó estudios de Derecho, se tituló de abogado, y al final de su dilatada carrera sería nombrado Caballero de la Orden de Carlos III ${ }^{(61)}$. Sobrino del Archivero Francisco Javier de Santiago, había nacido en Valencia y bautizado en la parroquia de San Juan del Mercado el 16 de 
junio de 1772. La rama familiar paterna procedía de Toledo, pero su padre Eugenio de Santiago, figura ser comerciante al por mayor establecido en Valencia, donde contrajo matrimonio con Josefa María Ferrer. La desahogada posición familiar le permitió cursar estudios universitarios y, posiblemente, deba el conocimiento de las lenguas francesa e inglesa a los negocios paternos ${ }^{(62)}$.

Entre sus trabajos en el Archivo resulta de gran interés el realizado en 1818 al arreglar el negociado de consulados y formar gran parte de los expedientes personales de los empleados de la Secretaría de Estado. La mayor parte de la documentación recopilada por Palomares tenía como objeto facilitar todo el proceso de certificaciones de servicios necesarias para acreditar la fidelidad a Fernando VII y la concesión de jubilaciones que resultaron de los numerosos arreglos del personal de la Secretaría y Ministerio de Estado a partir del final de la Guerra de la Independencia ${ }^{(63)}$.

\section{NOTAS}

(1) CORTÉS ALONSO, VICENTA: «Las ordenanzas de Simancas y la Administración castellana». En Actas del IV Symposium de Historia de la Administración. Madrid, 1983, pp. 197-200 y 223-224.

(2) Para el proceso de creación del Archivo de Simancas vid. CORTÉS ALONSO: Op. cit. pp. 202-205 y sobre todo PLAZA BORES, ÁNGEL: Archivo General de Simancas. Guía del Investigador. Madrid, $1980^{2}$, pp. 23-45. Extenso e interesante comentario archivístico de las normas dadas por la Instrucción de 24 de agosto de 1588 en la obra citada de CORTÉS ALONSO, pp. 213-223.

(3) Vid. CORTÉS ALONSO: Op. cit. pp. 215-216 y 222. PLAZA BORES: Op. cit., pp. 24-25, $27-28,32,39,49,93-95$.

(4) CORTÉS ALONSO: Op. cit., pp. 208-213 y 223, referido al Consejo de Indias.

(5) PLAZA BORES: Op. cit., pp. 51-52.

(6) Sobre esto MILLARES CARLÓ, AGUSTÍN: «El siglo XVIII español y las colecciones diplomáticas». En Filosofía y Letras, I, n. ${ }^{\circ}$ 2. abril-junio de 1941. (México), pp. 285-304 passim. GÓMEZ GÓMEZ, MARGARITA: «Crítica histórica y Archivos. El caso de España en el siglo XVIII». En Historia, Instituciones, Documentos, n. ${ }^{\circ} 12$, 1985, pp. 199-231, passim. MESTRE SANCHÍS, ANTONIO: Historia, fueros y actitudes politicas. Mayans y la historiografía del siglo XVIII. Valencia, 1970. Id.: Ilustración y Reforma de la Iglesia. Pensamiento político-religioso de Don Gregorio Mayans y Siscar (1699-1781). Valencia, 1968.

(7) CORTÉS ALONSO: Op. cit., pp. 198 y 204. PEÑA Y CÁMARA, JOSÉ DE LA: Archivo General de Indias de Sevilla. Guia del visitante. Valencia, 1958, pp. 41, 42-44, 48-49. SERRERA, RAMÓN MARÍA: «Manuel José de Ayala: un colaborador decisivo en el proyecto historiográfico de Juan Bautista Muñoz». En Semana Internacional de Archivos. Documentación y Archivos de la Colonización Española. La Rábida, 8-12 de octubre de 1979. Madrid, 1980, vol. II, p. 255. 
(8) HEREDIA HERRERA, ANTONIA: Archivistica General. Teoria y práctica. Sevilla, 1986, p. 78. La fecha a partir de la cual se consideraron estos documentos carentes de valor administrativo inmediato fue la de 1760: Vid. PEÑA CÁMARA: Op. cit., pp. 47-48.

(9) PLAZA BORES: Op. cit., pp. 59-60. MESTRE SANCHIIS, A.: Gregorio Mayans y Siscar. Epistolario II, Mayans y Burriel. Valencia, 1972, pp. XXXVIII-XLIV. OLAECHEA ALBISTUR, RAFAEL: Las relaciones Hispano-Romanas en la segunda mitad del siglo XVIII. La Agencia de Preces. Zaragoza, 1965, p. 43. GÓMEZ GÓMEZ: Op. cit., pp. 217-227.

(10) PLAZA BORES: Op. cit., pp. 49-50, 52-54, 58, 65, 66-67. PEÑA CÁMARA: Op. cit., pp. 41-43. En este sentido destaca el encargo hecho a don Santiago Agustín Riol, que dio lugar a su famoso informe, el 28 de enero de 1726. Vid. RIOL, S.: «Informe que hizo a Su Magestad en 16 de Junio de 1726 de su Real Orden Don Santiago Agustín Riol...» En Semanario Erudito, III, Madrid, 1787, pp. 75-76.

(11) RIOL: Op. cit., p. 85 (Secretaría del Despacho), p. 142 (Arreglo del Archivo de la Secretaría del Patronato por el Marqués de la Mejorada en 1688 y siguientes), pp. 165-166 (Arreglo del Archivo del Consejo de Órdenes por Don Joseph Antonio Severino), pp. 166-167 (Comisión a Don Luis de Salazar y Castro para visitar, clasificar e indizar los Archivos de las Órdenes Militares en Toledo, Uclés, Calatrava y Alcántara), pp. 177-178 (Comisión a Don Bernardo Muñoz Tovar para arreglar el Archivo del Consejo de Cruzada). SERRERA: Op. cit., pp. 253-254. HEREDIA HERRERA, A.: "Historia de un depósito documental: El Archivo del Consulado de Cargadores en Sevilla». En Actas de las Segundas Jornadas de Andalucía y América Andalucía y América en el siglo XVT. La Rábida, marzo de 1982. Sevilla, 1983, vol. I, pp. 492-494.

(12) RIOL: Op. cit., pp. 84-85.

(13) ESCUDERO, JOSÉ ANTONIO: Los Secretarios de Estado y del Despacho (1474-1724). Madrid, 1976. 4 vols. Id.: Los origenes del Consejo de Ministros en España. Madrid, 1979. 2 vols. 3444 '.

(14) Sobre los repartos de los negociados en la Secretaría de Estado, en A. H. N. Estado, leg.

(15) GÓMEZ DEL CAMPILLO, M.: Relaciones Diplomáticas entre España y los Estados Unidos. Madrid, 1949, I, p. V.

(16) GARCÍA DE LEÓN PIZARRO, J.: Memorias... p. 61. Sus impresiones sobre su toma de contacto con la Secretaría, el "gran serrallo» del favorito Godoy y los «serrallitos particulares pertenecientes a cada negociado», en pp. 37-54.

(17) RIOL: Op. cit., p. 178.

(18) MARTÍNEZ CARDOS, J.: Primera Secretaria de Estado. Ministerio de Estado. Disposiciones Orgánicas. Madrid, 1972. Apéndice, n. 2, pp. 6-7.

(19) ESCUDERO: Los Secretarios... vol. I, pp. 309-310.

(20) Representación de Don Benito Martínez Gómez Gayoso, «Sobre Montepío». Madrid, 31 10-1763. A. H. N. Estado, leg. 3449'.

(21) RIOL: Op. cit., p. 86. Vid. PLAZA BORES: Op. cit., pp. 57-58.

(22) LÓPEZ-CORDÓN CORTEZO, M. V.: «La primera Secretaría de Estado: la Institución, los hombres y su entorno (1714-1833). En Estudios de Historia Moderna y Contemporánea, n. ${ }^{\circ} 116$, Madrid, 1979, p. 23.

(23) Representación de Don Benito Martínez Gómez Gayoso, «Sobre Montepío». Madrid, 31 10-1763. A. H. N. Estado, leg. 3449 '.

(24) RIOL: Op. cit., pp. 142-144. OLAECHEA: Op. cit., pp. 36, 51, 179-180, 186-189. MALDONADO MACANAZ, J.: «Noticia biográfica», en Testamento Político. Pedimento Fiscal, Madrid, 1972, p. 62. BALDAQUÍ ESCANDELL, R.: Jansenismo y regalismo en el Semanario Erudito de Valladares. Tesis de Licenciatura inédita. Alicante, octubre de 1983, pp. 598-601.

(25) Sobre Juan Cascos y su labor diplomática en Holanda, A. G. S. Estado, leg. 6211, Correspondencia de N. Oliver y Juan Cascos (1726). La correspondencia de Líria desde Rusia en A. G. S. Estado, leg. 6610. Publicada en CODOIN «Diario del viaje a Moscovia, 1727-1730». T. XCIII (93), 
pp. 241-250. Por Real Cédula dada en Buen Retiro el 6-10-1783 se le expidió, a petición propia, el título en forma. En la minuta, de mano de Agustín de Montiano, figura la categoría de Oficial tercero. A. H. N. Estado, leg. 3449 '.

(26) Representación de Don Benito Martínez Gómez Gayoso, «Sobre Montepío». Madrid, 3110-1763. A. H. N. Estado, leg. 3449'.

(27) Juan de Iriarte, nacido en el Puerto de Santa Cruz el 15-12-1702. Cursó estudios en París desde 1713 y desde 1715 en Ruan con el P. Joanino. En el Colegio de Luis el Grande de París permaneció ocho años y adquirió una sólida formación en lenguas, filosofía y matemáticas. Después de una breve estancia en Londres, regresó a Tenerife hasta que en 1724 se trasladó a la Corte. Sobre su vida resulta imprescindible la obra redactada por su sobrino Bernardo y publicada como prólogo a la Gramática Latina (1771) y en las Obras sueltas (1774). VIERA Y CLAVIJO, hace un extracto biográfico en Noticias de la Historia General de las Islas Canarias. Madrid, Blas Román, 1777-1778, 4 vols. tomo IV, p. 584 y ss. También en SEMPERE Y GUARINOS,J.: Ensayo de una Biblioteca española de los mejores escritores del reynado de Carlos III. Madrid, 1785-1789, tomo VI, pp. 181-190. Un buen resumen en COTARELO Y MORI, E.: Iriarte y su época. Madrid, 1897.

(28) A. H. N. Estado, leg. 3444 '.

(29) Hijo de Benito Martínez y Juana Gómez, fue bautizado en la Iglesia Parroquial de Santa Cruz, en el lugar de Parada de Arriba, a los 12 dias de su nacimiento. Actuó de padrino Pedro Simón Ledesma, vecino de la Alberquería. Certificación de Bautismo por el Presbítero don Bartolomé López, fechada el 27-8-1757. A. H. N. Estado, leg. $3427^{2}$.

(30) Memorial de Don Benito Martínez Gómez Gayoso a S. M. s. f. [1770]. A. H. N. Estado, leg. 3449 '.

(31) Sobre Berzosa, vid. RIOL: Op. cit., p. 211 y «Carta de... al Rey dando gracias por haberle nombrado Archivero de la Embajada de España en Roma y cuenta de los trabajos realizados. Año

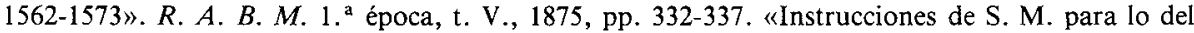
Archivio (sic). Año 1573». Ibidem, t. IV, 1874, pp. 125, 175, 191.

(32) Representación de Don Benito Martínez Gómez Gayoso, «Sobre Montepío». Madrid, 3110-1763. A. H. N. Estado, leg. 3449 '.

(33) Vid. MESTRE SANCHÍS, A.: «La Iglesia y el Estado. Los Concordatos de 1737 y 1753». En La época de los primeros Borbones. Historia de España, dirigida por Menéndez Pidal. v. I. pp. 237-333.

(34) PLAZA BORES: Op. cit., p. 60. Representación de Don Benito Martínez Gómez Gayoso, «Sobre Montepío». Madrid, 31-10-1763. A. H. N. Estado, leg. 3449'.

(35) Sobre el lance de Clavijo con Beaumarchais hay una abundante serie de referencias en las obras dedicadas a la literatura española del siglo XVIII. BAROJA, R.: Clavijo. Tres versiones de su vida. Barcelona, 1942. OLAECHEA, R.: «Un embajador veneciano en la España de Carlos III».En Cuadernos de Historia. Anexos de la Revista Hispania, n. ${ }^{\circ}$ 9, Madrid 1978, pp. 219-221. Vid. MILLARES CARLÓ, A.: Ensayo bio-bibliográfico de escritores naturales de Canarias (Siglos XVI, XVII y XVIII). Madrid, 1932. pp. 176-177. Sobre su etapa en el Real Gabinete de Historia Natural y referencias bibliográficas, PRADELLS NADAL, J.: «Valencianos en el Real Gabinete de Historia Natural. Siglo XVIII». En La Ilustración Española. Actas del Coloquio Internacional celebrado en Alicante. I-4 de octubre de 1985. Alicante, 1986, pp. 93-108.

(36) Sobre la colaboración de Palomares en los trabajos de Burriel vid. MESTRE SANCHÍS, A.: Gregorio Mayans v Siscar. Epistolario, II, Mayans y Burriel. Valencia, 1972, passim. Sobre sus cualidades caligráficas de grabador de láminas dan fe las que realizó para la Paleographia Hespañola, publicada a nombre de Esteban de Terreros y Pando. Madrid, Imprenta Real, 1785, pp. 201-360 del tomo XIII del Espectáculo de la Naturaleza del Abate M. Pluche. Vid. al respecto: "Noticias biográficas de Don Francisco Xavier de Santiago Palomares», en $B . R, A, H$., tomo LXXVI (1920) pp. 264-267. GIMENO BLAY, FRANCISCO: «Las llamadas ciencias auxiliares de la Historia, ¿errónea interpretación? (Consideraciones sobre el método de investigación en paleografía) Zaragoza, 1986, pp. 93-94. 
(37) Representación de Don Benito Martínez Gómez Gayoso, «Sobre Montepio». Madrid, 3110-1763. A. H. N. Estado, leg. 3449 '.

(38) A. H. N. Estado, leg. $3427^{\prime}$.

(39) En 5-4-1774, Gayoso recibió 50 doblones de ayuda de costa para el entierro de su primera esposa. En 28-5-1775, solicitó de Grimaldi el preceptivo permiso para contraer matrimonio con María Caro. A. H. N. Estado, leg. 3427 .

(40) Memorial de Belezar a S. M. Madrid, 6-7-1783. A. H. N. Estado, leg. 3449 !.

(41) Minuta adjunta al oficio de Floridablanca al Director General de Correos. San Ildefonso, 21-9-1783. A. H. N. Estado, leg. 3449'.

(42) A. de Monjardín-Cevallos, Madrid, 31-3-1808. Monjardín-Floridablanca, Madrid 12-101808, como Presidente de la Junta Suprema y Memorial a S. M., Madrid 5-6-1814. A. H. N. Estado, leg. $3449^{2}$.

(43) Aranda - Director General de Correos, Aranjuez, 17-4-1792. A. H. N. Estado, leg. 3449². El 17-8-1792 se reconocía a Monjardín el carácter de Oficial desde la fecha de su nombramiento, pero comenzando por la de octavo, lo que era una práctica nueva, pues hasta entonces habían gozado de consideración de terceros. Tras su salida, se llegó a nombrar a Mariano de Urquijo, pero un desplazamiento en las plazas de la Secretaría permitió su incorporación directa como Oficial. Vid. supra nota 42.

(44) A pesar de la justificación que Godoy hace en sus Memorias sobre su comportamiento con Anduaga, lo cierto es que las relaciones fueron muy tirantes con el Oficial que, al fin y al cabo, era uno de los floridablanquistas más conspicuos. PRÍNCIPE DE LA PAZ: Memorias. Madrid, 1965. 2 vols., I, p. 232, n. 34. GARCÍA DE LEÓN PIZARRO, J.: Memorias..., p. 41. El asunto significó la salida de Anduaga hacia el refrescante destino del Ministerio en Suecia. $3449^{2}$.

(45) Floridablanca - Marqués de Zambrano, El Pardo. 15-2-1784. A. H. N. Estado, leg.

(46) Palomares - Duque de la Alcudia [Madrid], 25-3-1794. A. H. N. Estado, leg. $3449^{2}$.

(47) España dividida en Provincias e Intendencias y subdividida en Partidos, Corregimientos, Alcaldes Mayores y Gobiernos, con su Diccionario de todos los pueblos. Madrid, 1790. Vid. LEÓN TELLO, P.: Op. cit., p. $97, \mathrm{n} .{ }^{\circ} 102$.

(48) La minuta es de finales de 1785, pues Palomares hacía constar 22 años de servicios con sueldo de 5.000 reales anuales y manifestaba su deseo de ser Oficial como, en efecto, se le hizo en 24-3-1786. Al margen de la solicitud Floridablanca anotó: «Los Yndices no guardan combinaciones. Hablaré con Palomares». Estado, leg. $3449^{2}$.

(49) Estado, leg. 3182 . Vid. LEÓN TELLO, P.: Un siglo de fomento español ( $A$ ños 1725-1825), Madrid, 1980, p. 97, n. ${ }^{\circ} 102$.

(50) Palomares - Duque de la Alcudia [Madrid], 25-3-1794. A. H. N. Estado, leg. $3449^{2}$.

(51) Anota Godoy sobre el Memorial de Palomares el 26-3-1794 la promoción de ambos a la vez que ordenaba que «Se conserven en el Archivo los papeles que vayan viniendo de Aranda y el Índice de Palomares». Estado, leg. 3449'. 3449 .

(52) Hurtado de Mendoza - Príncipe de la Paz, Madrid 13-1-1796. A. H. N. Estado, leg.

(53) Hurtado de Mendoza - Principe de la Paz, Madrid, 13-1-1796. Al tiempo que comunicaba la muerte de Palomares a Godoy. En la respuesta Godoy no tomó más decisión que la de encargarle el cuidado del Archivo. De nuevo insistiría Hurtado en otra representación fechada el 25-1-1796. A. H. N. Estado, leg. $3449^{2}$.

(54) MARQUÉS DE VILlA-URRUTIA. El Rey José Napoleón. Madrid, 1927, pp. 81-82.

(55) Optaban a la plaza, igualmente, el Archivero de la Secretaría de Guerra para Indias, Antonio Benito de Quintana; el ex-secretario del Marqués del Llano, Francisco Javier Ruiz de Mendoza; el secretario de la Inquisición de Corte, Manuel Anguiano; el Archivero de la Secretaría de Nueva España, Manuel Veloy; el ex-Oficial del Real Sitio de Aranjuez, Lorenzo Fernández Muñoz; y otros que con menor grado de cualificación, se apoyaban en notables influencias, hasta un total de 21 soli- 
citudes para Archivero y 11 más para la de Oficial. Son ejemplares las de Juan Antonio Romero, de 21 años, cuyo mérito principal era estar instruido en lenguas y ser hijo del Fiscal del Consejo de Indias; Antonio Pedro Bueno, empleado de Correos en México y anteriormente en Madrid; el abogado Cipriano Hernaiz y Marín; un Oficial de la Contaduría de Rentas Provinciales; Juan Francisco Díaz Serrano, que lo solicita por medio de su mujer, que había sido hermana de leche de la difunta Infanta María Isabel; el Oficial de la Contaduría de Rentas Generales, Benito Sáenz de Parayuelo; el capitán de las Milicias de Buenos Aires, Francisco de Paula y otros empleados en diferentes ramas de la Administración. Estado, leg. 3449². Sobre el «afrancesado» González Arnao, VAUCHELLEHAQUET, Aline: «Un afrancesado refugiado en Francia: Vicente González Arnao». En Trienio, Ilustración y Liberalismo. $\mathrm{n} .^{\circ}$ 9, mayo de 1987, pp. 179-182.

(56) P. de la Paz - Francisco Hurtado, Badajoz, 3-2-1796. Con la misma fecha recibe el de Oficial segundo del Archivo Santiago Montes, que había comenzado a servir en la Secretaría con Floridablanca. Floridablanca - Santiago Montes, El Pardo, 24-3-1786. A. H. N. Estado, leg. 3449 '.

(57) F. de Santiago Palomares - S. M. Madrid, 27-5-1795. Estado, leg. $3442^{2}$.

(58) Eduardo de Santiago - Secretario de Estado. Madrid, 3-4-1802. Estado, leg. $3442^{2}$.

(59) Rehabilitado en 1834, recibió la Cruz de Isabel la Católica en 12-9-1835. Su último ascenso de categoría data de 6-5-1837. Estado, leg. 3442².

(60) Nombrado por Real Orden de 19-6-1798, su sueldo era de 7.000 reales anuales. Estado, leg. $3442^{\prime}$.

(61) Oficial primero por Real Decreto de 7-1-1833, con 40.000 reales anuales. Fue jubilado por R. D. de 20-8-1834. Estado, leg. 3442'. Orden de Carlos III. Expediente 2243. Pruebas aprobadas en 19-9-1834. Nombrado por R. D. de 16-6-1833.

(62) Eugenio de Santiago era aficionado también al «proyectismo». En julio de 1786 presentó un proyecto para la creación de una Escuela o Cátedra de Comercio en Madrid o Valencia. A. H. N. Estado, leg. 3208, n. ${ }^{\circ}$ 377. LEÓN TELLO, P.: Un siglo de Fomento..., Madrid, 1980, p. 65, con una relación de méritos y servicios impresa fechada en Madrid el 17-3-1783.

(63) «Archivo. Razón de los trabajos executados por el Oficial Primero Palomares, 1818». Madrid, 18-2-1818. Estado, leg. 3442². 